\title{
The adaptation of MAIN to Vietnamese
}

\author{
Tue Trinh \\ Leibniz-Zentrum Allgemeine \\ Sprachwissenschaft
}

\section{Giang Pham}

San Diego State University

\section{Ben Phạm}

Hanoi National University of Education

\author{
Hien Hoang
}

Hanoi National College for Education

Linh Pham

Hanoi National College for Education

This paper describes the revision of the Vietnamese version of the Multilingual Assessment Instrument for Narratives (LITMUS-MAIN). We first introduce the Vietnamese language and Vietnamese-speaking populations after which we describe the translation and adaptation process of the Vietnamese MAIN and present results from monolingual and bilingual children.

\section{Introduction}

The Multilingual Assessment Instrument for Narratives (LITMUS-MAIN, hereafter MAIN; Gagarina et al., 2012, 2015), a picture-based narrative instrument, has been translated and adapted to many languages, of which the majority are Indo-European. This paper introduces the revised Vietnamese version, which is based on the revised English version of the MAIN (Gagarina et al., 2019). We first provide an overview of the Vietnamese language and Vietnamese-speaking populations worldwide. We then describe the translation and adaptation process of the Vietnamese MAIN and summarize how this tool has been used with Vietnamese monolingual children as well as bilingual children who speak Vietnamese and English.

\section{Overview of the Vietnamese language}

Vietnamese (tiếng Việt), which is the official language of the Socialist Republic of Vietnam, belongs to the Mon-Khmer branch of the Austroasiatic family. It is spoken as a native language 
by Vietnam's largest ethnic group, the Kinh, and is, for this reason, also called tiếng Kinh when it needs to be distinguished from the languages of other ethnic groups in the country. Below is a brief description of some aspects of Vietnamese grammar which can be considered to fall, roughly, under the headings of morphology, syntax, semantics and pragmatics, and which may seem particularly distinctive from the perspective of speakers of English and, more generally, of Indo-European languages.

Morphologically, Vietnamese is an isolating language, which means morpheme boundaries and syllable boundaries generally coincide. These boundaries are indicated in writing by empty spaces, which in English are used to mark word boundaries. The result is that Vietnamese texts often look like they contain more words than their English counterparts. To illustrate, the English title Multilingual Assessment Instrument for Narratives, comes out as Công cu Đánh giá Khả năng Tường thuật Đa Ngôn ngũ in Vietnamese. The isolating nature of Vietnamese also means that there is no inflection in the language: grammatical categories such as nominal case or verbal tense are not overtly expressed by affixes or changes in word form. Thus, tôi thích nó means 'I like him' or 'I liked him', and nó thích tôi means 'he likes me' or 'he liked me'.

Syntactically, Vietnamese is marked by its consistent left-headedness. Thus, verbs precede their complements and nouns precede their modifiers. To give an example, the sentence tôi thich sách cũ means 'I like old books', where cũ means 'old'. Vietnamese is also characterized syntactically by being a so-called in situ language, which means question words such as $a i$ 'who' and gi 'what' are not fronted but are instead pronounced in their thematic positions: nó thích ai means 'who does he like', for example.

Semantically, Vietnamese exemplifies a classifier language, which means its bare nouns have number neutral interpretation: tôi có chó (literally 'I have dog') is true when the speaker has one single dog, or when he has several dogs. In this respect, chó ' $\mathrm{dog}$ ' is similar to such English words as furniture. A consequence of this semantics is that chó cannot combine directly with a numeral, but requires the mediation of a classifier: *tôi có một chó (literally 'I have one dog') is as ungrammatical as *I have one furniture, while tôi có một con chó (literally 'I have one CL dog') where con is the classifier (CL) for animals, is as grammatical as I have one piece of furniture. This property of the noun chó generalizes to most other common nouns in the language.

Vietnamese is rich in resources which serve to encode such facets of meaning as can be called 'pragmatic,' i.e., those that relate to the language users and the context of communication. This is most clearly exemplified by the pronoun system, which is intricate and capable of expressing minute distinctions pertaining to the relative social positions of speaker and hearer, as well as their feelings and attitudes towards each other. As an example, in normal situations, a man refers to himself as anh when he speaks to his wife and as bố when he speaks to his child. In an angry argument with his wife, he may change self-reference from anh to tôi, or he may switch from bố to tao when yelling at his child. Discourse particles exemplify another class of items which are used to express pragmatic meanings. For example, the particle $a$, is appended to everything a well-behaved child says to an adult. The particles $\grave{u}$ and vâng, both of which express a meaning similar to that of English yes, differ in that $\grave{u}$ may be used in speaking 
to people of equal social rank, but when the hearer is to be shown respect and deference, vâng is obligatory.

\section{$3 \quad$ Vietnamese-speaking populations}

Vietnamese is the $18^{\text {th }}$ most commonly spoken language in the world (Simons \& Fennig, 2017). As the official language of Vietnam, it is spoken by most of the population accounting for over 95 million people from all 54 ethnic groups in the country. Approximately $86 \%$ of the population in Vietnam from the Kinh or Viet ethnic group speaks Vietnamese as the first language, and individuals from the remaining 53 ethnic minority groups speak Vietnamese as a second language in addition to their indigenous language (Trần, 2016).

Vietnamese is also spoken as a (minority) home language in many countries of the world. The Vietnam Ministry of Foreign Affairs (2012) estimates that the Vietnamese diaspora consists of about four million people. Over 1.5 million people of Vietnamese origin live in the US which makes Vietnamese the fifth most common home language in the country, after English, Spanish, Chinese, and Tagalog (U.S. Census, 2013). In Canada, Vietnamese is one of the top 25 languages spoken (Statistics Canada, 2012). In Australia, Vietnamese is the fourth most commonly spoken home language with $1.2 \%$ of the population (Australia Bureau of Statistics, 2017). Vietnamese is also recognized as a minority language in many European countries including Germany, France, the Czech Republic, Slovakia, Slovenia, and UK. For example, there are about 165,000 people with a Vietnamese migrant background living in Germany who are either Vietnamese nationals or German nationals with Vietnamese roots (Schaland \& Schmiz, 2015). In the Czech Republic, Vietnamese people are the third largest foreigner group (Czech Statistics Office 2018). In sum, there is a large number of Vietnamese speakers around the world, and many are likely to be bilingual or multilingual.

\section{$4 \quad$ Adapting MAIN to Vietnamese}

The first Vietnamese version of the MAIN, which was published in 2012, is a direct translation from the English version (Gagarina et al., 2012). The translator was Tue Trinh, a linguist and Vietnamese native speaker who worked at the Zentrum Allgemeine Sprachwissenschaft (ZAS), Berlin, Germany at the time.

The 2020 revision of the Vietnamese MAIN was a collaboration between Vietnamese colleagues in Vietnam, Germany, and the United States. When embarking on translation, it is important to consider linguistic equivalence as well as cultural equivalence (Peña, 2007). Linguistic equivalence is when the words and meaning in both versions are the same. One way to ensure linguistic equivalence is through expert consultation (Peña, 2007). To this end, the authors of this paper include individuals with high proficiency in Vietnamese and who have an educational background in linguistics, speech-language pathology, or education. Authors 
conducted independent reviews of the English and Vietnamese language versions to ensure that the Vietnamese translation was faithful to the English version from which it was adapted.

One challenge to achieving linguistic equivalence was in the use of specific terminology in Vietnamese. Many technical terms in English do not readily have standardized terms in Vietnamese. Careful attention was made to select terms in Vietnamese that reflected the original meaning of the English words. However, there are terms that will inevitably be unfamiliar to many Vietnamese speakers. We as authors of the Vietnamese version of the MAIN debated the use of certain terms (e.g., translations for protocol, picture sequence, story episode), and there were disagreements among group members. As the fields of language acquisition and disorders continue to develop for Vietnamese-speaking children, we will further discuss and refine the use of field-specific terminology in Vietnamese.

Beyond linguistic equivalence alone, cultural equivalence depends on the way members of different cultural and linguistic groups view or interpret question prompts and/or test items (Peña, 2007). Of key concern in the adaptation process was to verify that the Vietnamese MAIN would be accessible to different regional dialects of Vietnam as well as to Vietnamese-speaking communities outside of Vietnam. In order to do so, we had to consider dialectal variation and linguistic differences between the current language use in Vietnam and that of the Vietnamese diaspora. To illustrate, picture as in the picture sequences used in the MAIN is commonly translated as tranh in the northern region of Vietnam. However, tranh in Vietnamese-speaking communities outside of Vietnam means painting as in a large wall painting. Instead, hình is much more frequently used worldwide, which was the reason for its selection. This is just one example of how word selection for common terms used throughout the manual needed to be met with much consideration.

In cases where an object within a MAIN story had two labels depending on regional dialect, we presented both words for the examiner to choose. For example, balloon is bóng bay in the northern region of Vietnam and bong bóng in the southern region of Vietnam and in many communities outside of Vietnam. Another example is the word for ball, which is quả bóng in the northern region and trái banh in the southern region. In such cases, we included both labels so that the MAIN story models can be accessible to children across dialects.

\section{The use of MAIN with Vietnamese monolingual and bilingual children}

We have used the Vietnamese MAIN in our research projects with monolingual and bilingual children. In a study of monolingual Vietnamese children, G. Pham and colleagues (2019) administered the MAIN Cat and Dog stories as story retells to 104 children in kindergarten (aged 5;0 to 5;11) living in Hanoi, Vietnam. Children were classified into three groups: 45 children were considered to have typical language development, 49 children were at some risk of having developmental language disorder (DLD), and 10 children were classified as having DLD. We found that the story structure score of the MAIN was closely related to other language measures including tests of expressive vocabulary $(\mathrm{r}=.43, \mathrm{p}<.01)$ and receptive vocabulary $(\mathrm{r}=.52, \mathrm{p}<.01)$. Story structure scores also correlated with parental report measures of 
children's language skills $(\mathrm{r}=.26, \mathrm{p}<.01)$ and teachers $(\mathrm{r}=.36, \mathrm{p}<.01)$. Importantly, MAIN story structure scores distinguished between typically developing children and children with DLD, with a very large effect size $(\mathrm{d}=2.89)$. Thus, the MAIN stories and story structure scores show great potential for contributing to the accurate identification of DLD in Vietnamesespeaking children (for details, see G. Pham et al., 2019).

In a study of Vietnamese-English bilingual children, Dam and colleagues (in press) utilized data collected with MAIN to analyze the grammatical patterns of 89 children, aged 3 to 8 years. Children completed MAIN tasks in both Vietnamese and English. Following procedures outlined in the MAIN manual, MAIN Dog and Cat story retells were counterbalanced between languages (e.g., MAIN Cat in Vietnamese, MAIN Dog in English for one child and MAIN Cat in English and MAIN Dog in Vietnamese for another). Stories were audio recorded, transcribed using SALT software (Miller \& Iglesias, 2012) and scored for grammaticality and sentence complexity. Grammaticality was calculated as the number of grammatically correct utterances divided by the total number of utterances. The subordination index (SI) was calculated as the number of clauses divided by the total number of utterances. Dam and colleagues (in press) found a positive correlation between age and grammaticality in English, but not in Vietnamese. The lack of a correlation between Vietnamese and age suggested that older children had similar grammaticality scores as younger children, a possible indication of first language stagnation in this typically developing bilingual sample. However, SI in Vietnamese did correlate with age $(r=.38, p<.001)$, albeit to a lesser extent than the association between age and English SI $(r=.65, p<.001)$. This result indicates that bilingual children may be producing more complex sentence structures with age in both languages (for details, see Dam et al., in press).

\section{Conclusion}

This latest version of the Vietnamese MAIN has been carefully translated by a group of international experts to be faithful to the English original, use terms in Vietnamese that can be understood in Vietnam as well as by Vietnamese speakers worldwide. The MAIN has been shown to be a useful tool to assess various language skills in Vietnamese monolingual and bilingual children. Future studies can include a wider age range and the use of all four stories of the MAIN. Additionally, in order to increase its effectiveness as a diagnostic tool, a next step is to calculate diagnostic accuracy measures of sensitivity, specificity, and positive and negative likelihood ratios (Dollaghan, 2007) to verify whether the MAIN can identify DLD at the individual child level.

\section{$7 \quad$ References}

Australian Bureau of Statistics. (2017). Census reveals a fast changing, culturally diverse nation. http://www.abs.gov.au/ausstats/abs@.nsf/lookup/Media\%20Release3. 
Czech Statistics Office. (2018). Foreigners by type of residence, sex, and citizenship. https://www.czso.cz/csu/cizinci/number-of-foreigners-data\#rok

Dam, Q.D., Pham, G., Potapova, I., \& Pruitt-Lord, S. (in press). Grammatical characteristics of Vietnamese and English in developing bilingual children. American Journal of Speech-Language Pathology.

Dollaghan, C. A. (2007). The handbook for evidence-based practice in communication disorders. Paul H Brookes Publishing.

Gagarina, N., Klop, D., Kunnari, S., Tantele, K., Välimaa, T., Balčiūnienė, I., Bohnacker, U., \& Walters, J. (2012). MAIN: Multilingual Assessment Instrument for Narratives. ZAS Papers in Linguistics, 56.

Gagarina, N., Klop, D., Kunnari, S., Tantele, K., Välimaa, T., \& Balčiūnienè, I., Bohnacker, U., \& Walters, J. (2015). Assessment of narrative abilities in bilingual children. In S. Armon-Lotem, J. de Jong, \& N. Meir (Eds.), Assessing multilingual children: Disentangling bilingualism from language impairment (pp. 243276). Bristol: Multilingual Matters.

Gagarina, N., Klop, D., Kunnari, S., Tantele, K., Välimaa, T., Bohnacker, U., \& Walters, J. (2019). MAIN: Multilingual Assessment Instrument for Narratives - Revised. ZAS Papers in Linguistics, 63.

Peña, E. D. (2007). Lost in translation: Methodological considerations in cross-cultural research. Child development, $78,1255-1264$.

Pham, G., Pruitt-Lord, S., Snow, C.E., Nguyen, H.T.Y., Phạm, B., Dao, T.B.T., Tran, N.B.T., Pham, L.T., Hoang, H.T., \& Dam, Q.D. (2019). Identifying developmental language disorder in Vietnamese children. Journal of Speech, Language, and Hearing Research, 62, 1452-1467.

Schaland, A-J. \& Schmiz, A. (2015). The Vietnamese diaspora in Germany. Migration background, structure, organisations and transnational activities. https://www.cimonline.de/static/media/giz2016-en-vietnamdiaspora.pdf

Simons, G. F., \& Fennig, C. D. (2017). Ethnologue: Languages of the world (20th ed.). SIL International.

Statistics Canada. (2012). Linguistic characteristics of Canadians: Language, 2011 census of population. http://www12.statcan.gc.ca/census-recensement/2011/as-sa/98-314-x/98-314-x2011001-eng.cfm.

Trần, D. T. (2016). Ngôn ngũ các dân tộc thiểu số ở Việt Nam [Language of ethnic minorities in Vietnam]. Nhà xuất bản Đại học Quốc gia Hà Nội [Hanoi National University Publishing House].

U.S. Census Bureau. (2013). Infographics \& Visualizations: Top Languages Other than English

Spoken in 1980 and Changes in Relative Rank, 1990-2010. https://www.census.gov/dataviz/visualizations/045/

Vietnam Ministry of Foreign Affairs. (2012). Review of Vietnamese migration abroad. http://www.un.org.vn/en/publications/doc_details/387-review-of-vietnamese-migration-abroad.html. 